\title{
A sintaxe das construções de matéria e origem no Português Brasileiro
}

\author{
Adeilson Pinheiro Sedrins \\ Doutor em Linguística pela Universidade Federal \\ de Alagoas, Professor Adjunto de Língua \\ Portuguesa na Universidade Federal Rural de \\ Pernambuco, Unidade Acadêmica de Serra \\ Talhada (UFRPE/UAST) e líder do Grupo de \\ Estudos em Teoria da Gramática (GETEGRA).
}

Resumo: Este trabalho discute a sintaxe das construções de matéria e origem no português brasileiro, focalizando o padrão de extração apresentado por essas construções e contrapondo ao padrão encontrado para extração de construções genitivas. A análise desenvolvida, bem como a hipótese central para a explicação dos diferentes padrões de extração encontrados apontam para o fato de que a resistência à extração de adjuntos adnominais de matéria e origem deve-se à própria natureza categorial desses modificadores. A discussão apresentada toma como referencial teórico o Programa Minimalista, conforme apresentado em Chomsky (1995, 2000, 2001).

Palavras-chave: adjunto adnominal de matéria; adjunto adnominal de origem; genitivo; extração; sintaxe minimalista
Abstract: This paper discusses the syntax of adjuncts of origin and of material in Brazilian Portuguese, focusing on the extraction pattern brought by such constructions, in contrast to the pattern of extraction of genitive constructions. Both the analysis carried out and the central hypothesis for the explanation of the different patterns of extraction that were found point to the fact that the resistance to the extraction of adjuncts of origin and material is due to the own nature of category of these modifiers. The discussion presented takes the Minimalist Program, according to Chomsky (1995, 2000, 2001), as its theoretical reference.

Keywords: adjuncts of origin; adjuncts of material; genitive; extraction; minimalist syntax 



\section{Introdução}

Entre os sintagmas preposicionados introduzidos por de e que ampliam núcleos nominais no português brasileiro (PB), podemos encontrar, entre outras, construções denominadas genitivas (com interpretação semântica que varia entre agente, possuidor e tema ${ }^{1}$ ) e construções tradicionalmente classificadas como adjuntos adnominais, como é o caso de construções com interpretação de matéria, origem/procedência e tempo.

(1) a. A casa genitivo possuidor $_{\text {do Paulo] }}$

b. A destruição [ ${ }_{\text {genitivo tema }}$ da cidade]

c. A intervenção [ ${ }_{\text {genitivo agente }}$ do governo]

(2) a. Uma estante ${ }_{\text {adjunto adnominal de matéria }}$ de madeira]

b. O amigo [ ${ }_{\text {adjunto adnominal de origem }}$ de São Paulo]

c. O vaso [adjunto adnominal de origem/procedência da China ]

d. O livro [ ${ }_{\text {adjunto adnominal de tempo }}$ de 1986]

Embora os dois tipos de construções exemplificados acima sejam aparentemente de mesma natureza categorial, ou seja, sintagmas-de (sintagmas introduzidos pela preposição de), o comportamento sintático dessas construções, no que tange ao fenômeno da extração, não se dá de forma homogênea. Isto é, conforme observado em Sedrins (2009), enquanto o grupo dos genitivos parece poder ser livremente extraído para a periferia esquerda da sentença, os típicos adjuntos adnominais introduzidos por de se apresentam resistentes à extração, conforme verificamos nos exemplos de (3) a (5):

(3) a. O João quebrou a estante $\left[_{\text {adjunto }}\right.$ de madeira $]$ [genitivo $_{\text {da Maria]. }}$.

b. De quem (que) o João quebrou a estante de madeira?

c. ${ }^{*}$ De que (que) o João quebrou a estante da Maria? 
(4) a. O João quebrou um vaso $\left[_{\text {adjunto }}\right.$ da China $]\left[_{\text {genitivo }}\right.$ da Maria].

b. De quem (que) o João quebrou um vaso da China?

c. ${ }^{*}$ De onde (que) o João quebrou um vaso da Maria?

(5) a. $\quad{ }^{*}$ De que (que) o João quebrou a estante?

b. ${ }^{*}$ De onde (que) o João quebrou um vaso? (gramatical apenas com leitura locativa)

Assumindo as construções genitivas como construções de caráter argumental (cf. SEDRINS, 2009), poderíamos chegar à seguinte generalização, a partir do contraste verificado nos exemplos acima:

(6) No PB, sintagmas-de argumentais (ou sintagmas genitivos) podem ser livremente extraídos, mas não sintagmas-de que funcionam como típicos adjuntos adnominais.

Essa generalização remete a um contraste apontado em Huang (1982) e Chomsky (1986) entre a extração de um complemento nominal e de um adjunto adnominal em inglês. (7) mostra que a extração do complemento do nome destruction (destruição), em forma interrogativa, para o início da sentença, resulta numa construção gramatical, enquanto (8) mostra a agramaticalidade resultante da extração do adjunto adnominal de origem/ procedência:

(7) a. which city did you witness $\left[_{\mathrm{NP}}\right.$ the [destruction of which city]]

'de que cidade você presenciou a destruição?'

b. of which city did you witness $\left[_{\mathrm{NP}}\right.$ the [destruction of which city]]

'de que cidade você presenciou a destruição?'

(8) a. ${ }^{*}$ which city did you meet $\left[_{\mathrm{NP}}\right.$ the man $\left[_{\mathrm{PP}}\right.$ from which city]]

'de que cidade você encontrou o homem?' 
b. ${ }^{*}$ from which city did you meet $\left[_{\mathrm{NP}}\right.$ the man from which]

'de que cidade você encontrou o homem?'

O contraste nos dados do inglês verificado acima aponta para a validação da generalização em (6) também para essa língua ${ }^{2}$. Em direção contrária ao que é afirmado em (6), para o PB, casos de extração de sintagmas-de, apresentados em Avelar (2006), considerados por esse autor como adjuntos adnominais, mostram ser possível extrair esse tipo de modificador:

(9) a. De qual caixa a criança comeu [os bombons de qual eaixa]?

b. De qual porta o funcionário já trocou [a maçaneta de qual porta]?

Se o estatuto dos sintagmas-de em (9) for de adjunto adnominal, então a generalização em (6) não tem fundamento. No entanto, se considerarmos as relações semânticas estabelecidas pelos sintagmas preposicionados apresentados em (9), identificamos relações de continenteconteúdo (caixa e bombom) e de parte-todo (maçaneta e porta), as quais apresentam propriedades semelhantes a de construções genitivas.

Nesse sentido, valea pena destacaruma propriedade que distingue construções genitivas de construções que são típicos adjuntos adnominais. Milner (1982) observou que uma propriedade da construção genitiva no francês, entre outras, era a possibilidade de sua realização por uma forma pronominal possessiva. Muller (1997), baseada no trabalho de Milner, verificou que essa propriedade também é operante no português para a identificação de uma construção genitiva. Contrariamente, adjuntos adnominais não podem ser realizados sob uma forma pronominalizada, conforme mostra o contraste entre (10) e (11):

\author{
${ }^{2}$ A generalização em \\ (6) parece se estender \\ também a línguas \\ como o italiano e o \\ espanhol. Nessas línguas, \\ construções genitivas \\ podem ser extraídas \\ para fora do domínio \\ nominal, mas não \\ adjuntos adnominais \\ temporais, por exemplo \\ (Ver CINQUE, \\ 1980 e GIORGI \& \\ LONGOBARDI, 1991, \\ para o italiano, e \\ GUTIÉRREZ-BRAVO, \\ 2001, para o espanhol).
}


(10) a. A casa $\left[_{\text {genitivo possuidor }}\right.$ do Paulo] $>$ A sua casa $>$ A casa dele

b. A destruição [genitivo tema da cidade] $>$ A sua destruição $>$ A destruição dela

c. A intervenção genitivo agente $_{\text {do governo }]>A \text { sua }}$ intervenção > A intervenção dele

(11) a. Uma estante $\left[_{\text {adjunto adnominal de matéria }}\right.$ de madeira $]>$ *Uma estante sua

b. O amigo $\left[_{\text {adjunto adnominal de origem }}\right.$ de São Paulo $]>{ }^{*} \mathrm{O}$ seu amigo

c. O vaso $\left[_{\text {adjunto adnominal de origem/procedência }}\right.$ da China $]>{ }^{*} \mathrm{O}$ seu vaso

d. O livro [ adjunto adnominal de tempo de 1986] > $*$ seu livro

Observando os dados em (12), verificamos que o comportamento apresentado pelos sintagmasde apresentados em (9) se assemelha ao de construções genitivas, distinguido-se do comportamento de típicos adjuntos adnominais:

(12) a. Os bombons da caixa > Os seus bombons $>$ os bombons dela

b. A maçaneta da porta $>$ A sua maçaneta $>$ A maçaneta dela

A partir dessas considerações, buscaremos neste artigo discutir a sintaxe de dois tipos de relações semânticas realizadas por sintagmas-de no português: matéria e origem/ procedência. Nosso objetivo é descrever o comportamento sintático dessas construções no que tange, principalmente, ao fenômeno da extração. Conforme buscaremos mostrar, aparentes casos de extração dessas construções são decorrentes de diferentes configurações sintáticas: a realização sob forma de small clause para adjuntos de matéria e a realização como construção genitiva para supostos adjuntos de origem/procedência. 
A análise a ser apresentada nos levará a suspeitar que uma generalização como a exposta em (6) é atuante no $\mathrm{PB}$, o que nos direcionará a propor uma explicação para o fenômeno da extração baseada na teoria de checagem de traços, como apresentada em Chomsky (1995, 2000, 2001).

As próximas seções estão delineadas da seguinte forma: na seção 2, analisamos a estrutura sintática de relações de matéria no PB; na seção 3 , a estrutura sintática de relações de origem/procedência; na seção 4 , buscamos delinear uma proposta para explicar a resistência de extração de típicos adjuntos adnominais; por fim, na seção 5, apresentamos nossas considerações finais.

\section{A sintaxe de extração de adjuntos adnominais de matéria}

A partir do teste da pronominalização para identificação de constituintes, podemos constatar que as relações de matéria no PB podem ser geradas pelo menos de duas formas distintas: em forma de adjunto, dentro da construção nominal, ou numa configuração de small clause. A forma como o adjunto de matéria é realizado parece depender diretamente das propriedades de subcategorização do verbo da sentença. Assim, verbos do tipo querer e preferir podem apresentar como complemento uma small clause, em que se tem uma relação de matéria estabelecida, como mostram (13) e (15), a seguir. Por outro lado, verbos como quebrar e comer selecionam como complemento apenas DPs, dentro dos quais a relação de matéria é estabelecida, isto é, em configuração de típicos adjuntos adnominais, como mostram (14) e (16).

(13) a. O João quer/prefere [ ${ }_{S C}$ uma estante de madeira].

b. O João quer/ prefere [ela] [de madeira]

c. O João quer/prefere [ela] [toda de madeira] 
(14) a. O João quebrou [ ${ }_{D P}$ uma estante de madeira].

b. * 'O João quebrou [ela] [de madeira]

c. * * João quebrou [ela] [toda de madeira]

d. O João quebrou ela (=estante de madeira).

(15) a. O João quer/ prefere [ ${ }_{S C}$ um bolo de chocolate]

b. O João quer/prefere [ele] [de chocolate]

c. O João quer/prefere [ele] [todo de chocolate]

(16) a. O João comeu [ ${ }_{\mathrm{DP}}$ um bolo de chocolate].

b. ${ }^{*}$ O João comeu [ele] [de chocolate].

c. ${ }^{*} \mathrm{O}$ João comeu [ele] [todo de chocolate].

d. O João comeu ele (=o bolo de chocolate).

O padrão de extração do sintagma-de com interpretação de matéria vai ser distinto para cada uma das formas como é licenciado. Quando licenciado em configuração de small clause, o adjunto de matéria pode ser extraído para a periferia esquerda da sentença, mas não quando é licenciado como um típico adjunto adnominal, isto é, dentro do DP, como mostra o contraste entre os exemplos a seguir:

(17) a. O João quebrou [ ${ }_{D P}$ uma estante da madeira].

b. O João quebrou a/uma estante de quê?

c. *De que (que) o João quebrou uma/a estante?

(18) a. O João quer/prefere $\left[{ }_{S C}\right.$ a estante de que/de qual material]?

b. De que/qual material (que) o João quer/prefere a estante?

(19) a. Você comeu [ ${ }_{D P} \mathrm{o} / \mathrm{um}$ bolo de chocolate].

b. Você comeu o/um bolo de quê/de que sabor?

c. ${ }^{*}$ De que (que) você comeu um/o bolo?

(20) a. Você quer/prefere [ ${ }_{S C}$ o bolo de que/qual sabor]?

b. De que/qual sabor você quer/prefere o bolo? 
Os julgamentos de gramaticalidade podem variar em relação a (17c) e (18b), por exemplo, mas quando colocadas em contraste, (18b) soa bem melhor do que (17c). Da mesma forma, para alguns falantes consultados, quando (19c) é posto em contraste com (20b), este último exemplo soa bem melhor do que (19c). A questão que surge é por que a extração do sintagma-de de dentro de um DP resulta em uma sentença ruim, mas quando extraído a partir de uma construção de small clause o resultado é gramatical? Voltaremos a essa questão na seção 4, onde buscaremos delinear uma proposta para explicar o padrão de extração dessas construções. Na seção que segue, discutimos os casos dos adjuntos de origem/procedência.

\section{A sintaxe de extração de adjuntos adnominais de origem/procedência}

À primeira vista, parece que adjuntos adnominais de origem/procedência não podem ser extraídos no PB:

(21) a. O João encontrou [o amigo de São Paulo].

b. *De qual cidade o João encontrou o amigo de qual cidade?

(22) a. A Maria queimou [o tapete da China].

b. ${ }^{*}$ De onde/De que lugar a Maria queimou o tapete $^{3}$ de onde/de que lugar?

No entanto, um contraste interessante pode ser verificado entre DPs definidos e indefinidos, como o apresentado em (23) e (24):

(23) a. ??/*De qual cidade o João entrevistou [a garota de qual cidade]?

b. ??/* De que país o João beijou [a menina de que país]?

(24) a. De qual cidade o João entrevistou [várias garotas de qual eidade]? 
b. De que país o João beijou [algumas meninas de que país]?

O contraste entre (23) e (24) parece sugerir que um efeito de definitude pode estar atuando como restrição para a extração do adjunto de origem no $\mathrm{PB}$, indicando que a extração desse tipo de adjunto só é possível a partir de DPs indefinidos, como ocorre em (24), mas não de DPs definidos, como mostra (23). Todavia, o contraste de extração entre (23) e (24) parece não estar diretamente ligado à questão de definitude do DP, mas ao fato de que de qual cidade/país, em cada um desses exemplos, apresenta configurações sintáticas distintas. A diferença básica entre as duas construções é que, em (23), o sintagama-de é um verdadeiro adjunto de origem, enquanto que em (24) apresenta comportamento de uma construção genitiva.

Uma propriedade interessante entre os exemplos acima consiste no fato de que em (23) não podemos substituir o sintagma-de por uma forma pronominal possessiva, contrariamente ao que acontece com o sintagma-de em (24). Ambos os exemplos são retomados em (26), onde o contraste pode ser verificado.

(26) a. O João entrevistou [a garota daquela cidade/ país] > * O João entrevistou a sua (= cidade/país) garota/garota dela.

b. O João entrevistou [várias garotas daquela cidade/país] > O João entrevistou várias garotas suas/garotas dela (=daquela cidade/país).

A possibilidade de ser realizado pela forma pronominal possessiva pode indicar que o adjunto adnominal em (24) constitui na verdade um caso de construção genitiva, uma vez que compartilha de mesma propriedade (a possibilidade de pronominalização por forma possessiva). O sintagma-de em (23), por outro lado, caracteriza-se como um típico adjunto de origem. 
Note-se que a leitura para as construções nominais na posição de objeto em (24) é semelhante à leitura de construções que designam parte-todo, e não necessariamente uma relação de origem/procedência.

Dessa forma, casos de aparentes adjuntos de origem, os quais podem ser interpretados como uma relação de parte-todo, juntamente com o nome que modificam, como os apresentados a seguir, são, na verdade, casos de construções genitivas e, como tais, podem ser extraídas:

(27) a. O João entrevistou [várias garotas de Maceió].

b. Maceió tem várias garotas.

c. O João entrevistou várias garotas suas (=de Maceió).

d. De qual cidade o João entrevistou várias garotas?

(28) a. O João visitou muitas praias de Maceió.

b. Maceió tem muitas praias.

c. O João visitou muitas praias suas (=de Maceió).

d. De qual cidade o João visitou muitas praias?

(29) a. A Maria fotografou [alguns monumentos históricos de São Paulo]

b. São Paulo tem alguns monumentos históricos.

c. A Maria fotografou alguns monumentos históricos seus (= de São Paulo)

d. De qual cidade a Maria fotografou alguns monumentos históricos?

As construções que não permitem a leitura de parte-todo, como as apresentadas em (30) e (31), seriam, então, exemplos típicos de construções em que temos adjuntos de origem. Note-se que nesses casos, a extração do sintagma-de não é possível:

(30) a. O João encontrou [o amigo de São Paulo] (*São Paulo tem um amigo) 
b. ${ }^{*}$ De onde/de que cidade o João encontrou o amigo?

(31) a. A Maria queimou um tapete da China. (*A China tem um tapete)

b. ${ }^{*}$ De onde a Maria queimou um tapete?

O contraste de extração entre um típico adjunto de origem (32) e uma construção do tipo parte-todo (33) é dado a seguir:

(32) a. A Maria quebrou [um vaso da Índia]. ( ${ }^{*}$ A Índia tem um vaso)

b. *De onde /de que país a Maria quebrou um vaso?

(33) a. A Maria quebrou [um vaso da sala]. (A sala tem um vaso)

b. De onde a Maria quebrou um vaso?

A partir do exposto nesta e na seção anterior, pudemos constatar que quando interpretados e projetados como típicos adjuntos adnominais, isto é, projetados dentro de construções nominais, os sintagmas-de de matéria e origem/procedência mostram-se resistentes à extração. Na seção que segue, buscaremos acomodar essa propriedade dos típicos adjuntos dentro do quadro teórico da teoria de checagem de traços, como apresentada em Chomsky (2000). Iremos argumentar que a resistência à extração deve-se à natureza categorial desses adjuntos que, diferentemente de genitivos, não podem entrar em relações de checagem com núcleos funcionais dentro da estrutura nominal e, por este motivo, não podem mover-se para fora do domínio nominal, uma vez que o movimento sintático é engatilhado por necessidade de satisfação de requerimentos gramaticais através da checagem de algum traço morfossintático. 


\section{Especulações sobre por que adjuntos adnominais não podem ser extraídos}

O esboço de nossa proposta é baseado na discussão apresentada em Chomsky (2000, 2001). Uma ideia crucial no modelo de gramática discutido nas referidas obras é a de que os objetos linguísticos que entram na derivação sintática são uma combinação de traços, que podem ser de natureza semântica, fonológica e, ainda, formal. Às operações sintáticas cabe o papel de separar traços semânticos de traços fonológicos, permitindo que para cada nível de interface sejam enviados apenas traços legíveis (traços fonológicos para a componente fonológica e traços semânticos para a componente semântica). Além disso, cabe também às operações sintáticas o apagamento de traços formais não-interpretáveis, a fim de garantir legibilidade pela componente semântica. Nesse sentido, categorias funcionais como $\mathrm{T}$, por exemplo, seriam constituídas de traços interpretáveis (de tempo e modo, por exemplo) e não-interpretáveis (como número, pessoa e EPP), os quais precisam ser valorados contra traços interpretáveis de algum outro objeto presente na estrutura. T, então, sonda a estrutura sintática a fim de estabelecer uma relação de concordância, através da valoração de seus traços com outro objeto sintático, permitindo, após essa valoração, o apagamento de seus traços não-interpretáveis.

Nesse modelo de gramática, a concordância entre sujeito e o núcleo flexional da sentença seria interpretada como uma relação estabelecida entre T e o DP sujeito, em que $T$ valora seus traços- $\varphi$ não-interpretáveis contra os traços- $\varphi$ interpretáveis do DP. Além de traços- $\varphi$ nãointerpretáveis, $\mathrm{T}$ também seria composto de um traço [EPP], por exemplo, que, em termos de Chomsky (2000), pode ser definido como um traço de natureza formal nãointerpretável que exige a presença de um objeto na posição de especificador da categoria que o apresenta. Assim, a eliminação desse tipo de traço formal não-interpretável estaria condicionada a essa condição. 
Além da teoria de verificação/checagem de traços esboçada brevemente acima, três outras premissas serão adotadas em nossa proposta. A primeira é a que diz respeito à estrutura do sintagma de determinante no português, para a qual estamos assumindo a existência de, pelo menos, uma categoria NP (sintagma nominal, ou, nominal phrase, no inglês), uma categoria NumP responsável pelo estabelecimento de relações de concordância, nos termos em que é proposto em Ritter (1991) e a própria categoria DP, nos termos em que é proposto em Abney (1987). A estrutura básica do DP assumida neste trabalho é apresentada em (34):

(34) Estrutura básica do DP no PB

$$
\left[{ }_{D P}\left[{ }_{N u m P}[N P]\right]\right.
$$

A segunda premissa é a de que o DP constitui uma fase, seguindo a proposta de Svenonius (2004), Sedrins (2009). Uma fase pode ser definida como um domínio em que apenas a periferia (ou seja, a posição de especificador) e o núcleo estão disponíveis para operações sintáticas posteriores (cf. Chomsky, 2001). Assim, para que um elemento possa ser extraído para fora do DP, este deve estar disponível na sua periferia, ou seja, na posição de especificador de DP.

A terceira premissa diz respeito à natureza nominal de construções genitivas. Típicas construções genitivas seriam manipuladas na sintaxe como verdadeiros DPs, havendo inserção tardia (pós-sintática) da preposição de. Essa ideia é apresentada em Avelar (2006) e assumida no presente trabalho.

Dadas essas premissas, nossa hipótese é a de que a possibilidade de um constituinte ocupar a posição de especificador de $\mathrm{DP}$, no $\mathrm{PB}$, está condicionada à possibilidade de este constituinte checar um traço de $\mathrm{D}$, provavelmente um traço formal não-interpretável [EPP]. As construções genitivas, como verdadeiros DPs, 
poderiam checar o traço [EPP] de $\mathrm{D}$, mas não um adjunto de matéria ou de origem provavelmente porque seriam verdadeiros PPs ou teriam traços mais semelhantes aos de um adjetivo. Essa proposta encontra um paralelismo entre o domínio do DP e o domínio da sentença, se atribuirmos a $\mathrm{D}$ um papel semelhante ao que $\mathrm{T}$ desempenha na sentença: seguindo Chomsky (2000), é o traço [EPP] de $\mathrm{T}$ que engatilha o movimento do DP sujeito para sua posição de especificador. Da mesma forma, o traço [EPP] de $\mathrm{D}$ engatilharia o movimento de um genitivo para sua posição de especificador.

Um tipo de análise similar é apresentado em Gutiérrez-Bravo (2001), para quem o padrão de extração a partir de DPs, no espanhol, está condicionado à possibilidade de o constituinte a ser extraído poder checar um traço de Caso de AgrGen e também ao mesmo tempo um traço de natureza interrogativa [wh] em D. AgrGen, na proposta do autor, é uma categoria projetada logo abaixo de DP e onde o Caso genitivo é atribuído, algo equivalente à projeção NumP de Ritter (1991). AgrGen é um núcleo que se move para D e, então, a possibilidade de um constituinte ir para a posição de especificador do DP, posição mais proeminente da construção nominal, na proposta do autor, está condicionada pela possibilidade de esse constituinte poder checar tanto um traço wh de D, quanto o traço de Caso de AgrGen. Se um constituinte se move para [Spec, DP] checando com D o traço wh, mas não checando o traço de Caso de AgrGen, a derivação fracassa. Nessa proposta, o Caso checado/atribuído por AgrGen é o genitivo. Assim, apenas genitivos podem ser alçados para [Spec, DP], uma vez que apenas esses podem checar o traço de AgrGen.

Uma evidência para o tratamento diferenciado entre as construções genitivas e os adjuntos adnominais de matéria e origem no $\mathrm{PB}$, assumindo os genitivos como verdadeiros DPs e os adjuntos como categorias de outra natureza (preposicional ou adjetiva) pode ser verificada 
diacronicamente em relação ao uso da preposição de. Como verificou Poggio (2002), originalmente, a preposição de no português era usada para indicar as relações de matéria e origem, e apenas gradativamente o uso dessa preposição foi estendido para introduzir outros adjuntos do nome. Dessa forma, além da marcação casual, haveria a necessidade do uso da preposição para delinear a noção de matéria e origem, indicando que além do papel de um mero realizador de Caso, a preposição de em tais contextos exerceria mais alguma função (provavelmente relacionada a papel temático). Se este for o caso, não seria improvável postular que essa preposição, diferente do que ocorre com construções genitivas, já está introduzindo o adjunto quando este é concatenado à estrutura, na sintaxe.

Interlinguisticamente, podemos verificar no inglês, por exemplo, que a relação de matéria e origem dentro de sintagmas nominais é realizada de forma distinta de como são realizadas as construções genitivas. A preposição que introduz relações de origem/procedência (from) é diferente da preposição que introduz genitivos (of). Ainda, a relação de matéria em construções nominais pode se dar tanto com o uso do elemento funcional of (36a), ou com uma forma adjetiva (36b):

(35) a. The destruction of the city

b. The man from São Paulo

(36) a. The cake of chocolate

b. The chocolate cake

Também no português as relações de matéria podem ser estabelecidas através do uso de formas adjetivas, como em bolo achocolatado, estante madeirada etc, evidenciando o caráter adjetival dessas construções. 


\section{Considerações finais}

Diante dos casos de extração discutidos neste artigo, pudemos verificar uma resistência na extração de sintagmas-de interpretados como matéria e origem/ procedência, quando nitidamente esses sintagmas são projetados como típicos adjuntos adnominais. Conforme buscamos discutir na seção anterior, a agramaticalidade resultante da extração de adjuntos adnominais de matéria ou de origem, no $\mathrm{PB}$, poderia estar atrelada à impossibilidade de esses modificadores entrarem em relação de checagem com o traço $[\mathrm{EPP}]$ de $\mathrm{D}$, devido à natureza não-nominal desses adjuntos, diferentemente de construções genitivas que teriam estatuto de DP na derivação sintática. Se a possibilidade de extração de um constituinte para fora do DP estiver condicionada à possibilidade de este checar o traço [EPP] de D e se esse traço só puder ser checado por categorias de natureza DP (ou NP), então a generalização apresentada em (6), na introdução deste artigo, poderia ser reescrita da seguinte forma:

(37) No PB, sintagmas preposicionados manipulados na sintaxe como verdadeiros DPs (inclua-se aí toda construção genitiva) podem ser livremente extraídos para fora do DP, mas não sintagmas que já na sintaxe são encabeçados por preposição.

Se (37) é uma generalização aplicada ou não ao $\mathrm{PB}$, somente outras análises acuradas sobre o fenômeno da extração nessa língua poderão responder. 


\section{Referências}

AVELAR, J. O. de. Adjuntos adnominais preposicionados no português brasileiro. Campinas, 2006. Tese de doutorado, UNICAMP.

CHOMSKY, N. Barriers. Cambridge, Massachusetts: The MIT Press, 1986.

CHOMSKY, N. The Minimalist Program. Cambridge, MA: MIT Press, 1995.

CHOMSKY, N. Minimalist Inquiries: the framework. In: MARTIN, R.; MICHAELS, D.; URIAGEREKA, J. Step-byStep: Essays in Minimalist Syntax in Honor of Howard Lasnik. Cambridge, Massachusetts: The MIT Press, 2000.

CHOMSKY, N. Derivation by phase. In: KENSTOWICZ, M. Ken Hale: A Life in Language. Cambridge, Massachusetts: The MIT Press, 2001.

CINQUE, G. On extraction from NP in Italian. In: CINQUE, G. Italian syntax and universal grammar. Cambridge University Press. 1980.

GIORGI, A. \& LONGOBARDI, G. The Syntax of Noun Phrases. Cambridge: Cambridge University Press, 1991.

GUTIÉRREZ-BRAVO, R. Phases, Case and Accessibility: the Case of Extraction from DP in Spanish. In: McCLOSKEY, J. (ed.). Syntax and Semantics at Santa Cruz 3. Santa Cruz: University of California, 2001

HUANG, J. Logical Relations in Chinese and the Theory of Grammar. Cambridge, Mass., 1982. PhD dissertation. MIT.

MILNER,J-C. Ordres et raisons de langue. Paris: le Seuil, 1982. 
MÜLLER, A. L. P. A gramática das formas possessivas no português do Brasil. Tese de doutorado, UNICAMP,1997.

RITTER, E. Two Functional Categories in Noun Phrases: evidence from Modern Hebrew. In: ROTHSTEIN, S. (org.). Perspectives on Phrase Structure. Syntax and Semantics, 26. New York: Academic Press, 1991.

SEDRINS, A. P. Restrições de extração de argumentos e adjuntos de nome no português brasileiro. Maceió, 2009. Tese de doutorado, UFAL.

SVENONIUS, P. On the edge. In: ADGER, D.; de CAT, C.; TSOULAS, G. Peripheries: Syntactic Edges and Their Effects. Netherlands: Kluwer Academic Publishers, 2004.

POGGIO, R. M. G. F. Processos de gramaticalização de preposiçôes do latim ao português: uma abordagem funcionalista. Salvador: EDUFBA, 2002. 